\title{
The genome of Paenibacillus sabinae T27 provides insight into evolution, organization and functional elucidation of nif and nif-like genes
}

Xinxin $\mathrm{Li}^{1,2+}$, Zhiping Deng ${ }^{1 \dagger}$, Zhanzhi Liu ${ }^{1 \dagger}$, Yongliang Yan ${ }^{3 \dagger}$, Tianshu Wang ${ }^{1}$, Jianbo Xie ${ }^{1}$, Min Lin ${ }^{3}$, Qi Cheng ${ }^{3}$ and Sanfeng Chen ${ }^{1,2^{*}}$

\begin{abstract}
Background: Most biological nitrogen fixation is catalyzed by the molybdenum nitrogenase. This enzyme is a complex which contains the MoFe protein encoded by nifDK and the Fe protein encoded by nifH. In addition to nifHDK, nifHDK-like genes were found in some Archaea and Firmicutes, but their function is unclear.

Results: We sequenced the genome of Paenibacillus sabinae T27. A total of 4,793 open reading frames were predicted from its $5.27 \mathrm{Mb}$ genome. The genome of $P$. sabinae T27 contains fifteen nitrogen fixation (nif) genes, including three nifH, one nifD, one nifK, four nifB, two nifE, two nifN, one nifX and one nifV. Of the 15 nif genes, eight nif genes (nifB, nifH, nifD, nifK, nifE, nifN, nifX and nifl) and two non-nif genes (orf1 and hesA) form a complete nif gene cluster. In addition to the nif genes, there are nitrogenase-like genes, including two nifH-like genes and five pairs of nifDK-like genes. IS elements on the flanking regions of nif and nif-like genes imply that these genes might have been obtained by horizontal gene transfer. Phylogenies of the concatenated 8 nif gene (nifB, nifH, nifD, nifK, nifE, nifN, nifX and nifl) products suggest that $P$. sabinae T27 is closely related to Frankia. RT-PCR analysis showed that the complete nif gene cluster is organized as an operon. We demonstrated that the complete nif gene cluster under the control of $\sigma^{70}$-dependent promoter enabled Escherichia coli JM109 to fix nitrogen. Also, here for the first time we demonstrated that unlike nif genes, the transcriptions of nifHDK-like genes were not regulated by ammonium and oxygen, and nifH-like or nifD-like gene could not restore the nitrogenase activity of Klebsiella pneumonia nifH ${ }^{-}$and nifD- mutant strains, respectively, suggesting that nifHDK-like genes were not involved in nitrogen fixation.
\end{abstract}

Conclusions: Our data and analysis reveal the contents and distribution of nif and nif-like genes and contribute to the study of evolutionary history of nitrogen fixation in Paenibacillus. For the first time we demonstrated that the transcriptions of nifHDK-like genes were not regulated by ammonium and oxygen and nifHDK-like genes were not involved in nitrogen fixation.

Keywords: Paenibacillus sabinae T27, nif gene cluster, nif-like gene, Genome sequence

\footnotetext{
*Correspondence: sanfeng_chen@126.com

${ }^{\dagger}$ Equal contributors

'Key Laboratory for Agrobiotechnology, Ministry of Agriculture, China

Agricultural University, Beijing 100193, P. R. China

${ }^{2}$ Key laboratory of Soil Microbiology, Ministry of Agriculture, China

Agricultural University, Yuanmingyuan west road no.2, Haidian District,

Beijing 100193, P. R. China

Full list of author information is available at the end of the article
}

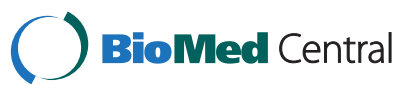

(c) 2014 Li et al.; licensee BioMed Central Ltd. This is an Open Access article distributed under the terms of the Creative Commons Attribution License (http://creativecommons.org/licenses/by/2.0), which permits unrestricted use, distribution, and reproduction in any medium, provided the original work is properly credited. The Creative Commons Public Domain Dedication waiver (http://creativecommons.org/publicdomain/zero/1.0/) applies to the data made available in this article, unless otherwise stated. 


\section{Background}

Biological nitrogen fixation, the conversion of atmospheric $\mathrm{N}_{2}$ to $\mathrm{NH}_{3}$, plays an important role in the global nitrogen cycle and in world agriculture [1]. Most biological nitrogen fixation is catalyzed by the molybdenum nitrogenase. This enzyme is a complex which contains the MoFe protein encoded by nifDK and the Fe protein encoded by nifH. The MoFe protein contains two metalloclusters: FeMo-co, a [Mo-7Fe-9S-C-homocitrate] cluster which serves as the active site of substrate binding and reduction and the P-cluster, a [8Fe-7S] cluster which shuttles electrons to FeMo-co [2,3]. Previous biochemical and genetic studies on Klebsiella pneumoniae carrying twenty nif genes on 24-kb region genes and Azotobacter vinelandii revealed that nifH, nifD, nifK, nifE, nif $N$, nifX nifB, nifQ, nif $V$, nif $Y$, nif $U$ nifS, nifZ and nifM contribute to the synthesis and maturation of nitrogenase $[2,3]$.

Contents and organization of nif genes varied significantly among $\mathrm{N}_{2}$-fixing organisms. For example, in K. pneumoniae, twenty nif genes are co-located within a $\sim 24 \mathrm{~kb}$ cluster [4], whereas in $A$. vinelandii the nif genes are more dispersed and distributed as two clusters in genome [5]. There is usually only one nifH gene and the nifH, nifD and nifK genes are transcribed as a single unit in many diazotrophs, such as $K$. pneumoniae and $A$. vinelandii. However, multiple nifH genes were found in a few diazotrophs. For examples, Rhizobium leguminosarum bv. phaseoli possesses three nifH genes [6] and Clostridium pasteurianum W5 has six nifH homologs [7].

Nitrogen fixation is sporadically distributed among prokaryote families: Proteobacteria, Firmicutes, Archaea, Cyanobacteria and Actinobacteria [8]. The incomplete distribution pattern and the difference in contents and organization of nif genes raise the question of origins and evolution of Mo-nitrogenase. Two conflicting hypotheses for the origin of Mo-nitrogenase have been proposed on the basis of phylogenetic examination of Mo-nitrogenase protein sequences (NifHDK) [9]. The last common ancestor (LCA) hypothesis implies that the Mo-nitrogenase had its origin in a common ancestor of the bacterial and archaeal domains. According to the LCA model gene loss has been extensive and accounts for the fact that nitrogenase is found neither in eukaryotes nor in many entire phyla of prokaryotes. The Methanogen origin hypothesis implies that nitrogen fixation originated from methanogenic archaea and subsequently was transferred into a primitive bacterium via lateral gene transfer. Recent studies based on phylogenetic analysis of NifHDK sequences supported the Methanogen origin hypothesis and implied that Mo-nitrogenase evolved in the anaerobic and hydrogenotrophic methanogens with acquisition in the bacterial domain via lateral gene transfer involving an anaerobic member of the Firmicutes [10].
Firmicutes have been thought to play an important role in evolution of nitrogen fixation. Studies on evolution of nitrogen fixation in Firmicutes mainly focused on the anaerobic diazotrophic Clostridia. Although Paenibacillus is a genus of Firmicute, its nitrogen fixation traits and evolution remains unclear. It is well known that Paenibacillus is a genus of Gram-positive, facultative anaerobic, endospore-forming bacteria, originally included within the genus Bacillus and then reclassified as a separate genus in 1993 [11]. Bacteria belonging to this genus have been detected in a variety of environments such as soil, water, rhizosphere, vegetable matter, forage and insect larvae, as well as clinical samples [12]. Nitrogen-fixing Paenibacillus species have great potential for use as a bacterial fertilizer in agriculture, but genomic information of these bacteria is lacking.

Here we report the complete genome sequence of $P$. sabinae T27 which is a nitrogen-fixer isolated from the rhizosphere of plant Sabina squamata by our laboratory [13]. The whole genome analysis not only reveals the organization and distribution of nitrogen-fixing genes and nitrogenase-like genes, but also provides insight into the evolution of nif genes in Paenibacillus. Furthermore, we demonstrate that the complete nif gene cluster consisting of ten genes (nifB, nifH, nifD, nifK, nifE, nifN, nifX, orf1, hes $A$ and nifV) of P. sabinae T27 is a functional unit for nitrogen fixation. Here for the first time we demonstrated that nifHDK-like genes are not involved in nitrogen fixation.

\section{Results and discussion}

\section{General features of Paenibacillus sabinae T27 genome}

The complete genome of $P$. sabinae T27 is composed of a single circular molecule of 5,270,569 base pairs (bp) with an average $\mathrm{G}+\mathrm{C}$ content of $52.64 \%$. The circular chromosome has a total of 4,849 putative protein-coding sequences (CDS), 26 rRNAs (8 copies of 16S-23S-5S operons and 1 copy of $16 \mathrm{~S}-23 \mathrm{~S}$ operon) and 82 tRNAs (Table 1). Among the predicted genes, 3,538 were assigned

Table 1 General features of the genome of $P$. sabinae T27

\begin{tabular}{ll}
\hline Attribute & Value \\
\hline Complete genome size, bp & $5,270,569$ \\
G + C\% & 52.64 \\
Protein-coding sequences & 4,849 \\
Genes with assigned function & 3,538 \\
Genes with unknown function & 1,311 \\
Average CDs size & 941 \\
Percent of coding region\% & 72.96 \\
No. of rRNAs & 26 \\
No. of tRNAs & 82 \\
Insertion sequence (IS) elements & 28 \\
\hline
\end{tabular}


putative functions, covering $72.96 \%$ of the genome, and 1,311 encoded hypothetical proteins (Table 1). Twenty eight insertion sequence (IS) elements were identified in the $P$. sabinae T27 genome.

\section{Comparative genomics of $P$. sabinae T27}

Previous phylogeny based on nifHDK showed that Firmicutes, cyanobacteria and actinobacteria are closely related [10]. Here we compared the genomes of P. sabinae T27, Clostridium acetobutylicum ATCC 824 (a member of Firmicutes), Frankia sp. CcI3 (an actinobacterium) and Nostoc punctiforme PCC 73102 (a cyanobacterium). The four species had the core genome of 258 putative proteincoding genes (Figure 1A). There are 802 genes which are shared by $P$. sabinae T27and $C$. acetobutylicum ATCC 824, there are 454 genes which are shared by P. sabinae T27and Frankia sp. CcI3, and there are 553 genes which are shared by $P$. sabinae T27 and N. punctiforme PCC 73102. The shared genes by P. sabinae T27and C. acetobutylicum are more than those shared by $P$. sabinae T27with Frankia sp. CcI3 or N. punctiforme. The results are consistent with the fact that Paenibacillus is more closely related to Clostridium than to Frankia and cyanobacteria, since Paenibacillus and Clostridium belong to the same Firmicutes. Furthermore, the genome of P. sabinae T27 was compared with those of the closely related Paenibacillus azotofixans ATCC35681 (a nitrogen-fixer) [14] and Paenibacillu polymyxa SC2 (a non-nitrogen-fixer) [15] (Figure 1B). Genome sizes of P. sabinae T27, P. azotofixans ATCC35681 and $P$. polymyxa SC2 are 5.27 Mb, 5.44 Mb and 6.24 Mb, respectively. Chromosome alignments showed higher level of conservation of genome architecture between P. sabinae
T27 and P. polymyxa SC2 than that between P. sabinae T27 and P. azotofixans ATCC35681.

\section{Central metabolism}

$P$. sabinae T27 is a nitrogen-fixing bacterium isolated from the rhizosphere of the plant Sabina squamata [13]. The bacterium contains a wide spectrum of genes for carbon utilization and carbohydrate, amino acid and inorganic ion transport. The genome of P. sabinae T27 contains the complete set of genes for the pentose phosphate pathway (PPP) (Additional file 1: Figure S1). In addition to the metabolism of pentose, the non-oxidative PPP allows the production of intermediates necessary for nucleic acid synthesis. It contains the complete set of genes for the glycolysis pathway and allows production of acetyl-CoA. In the presence of external electron acceptors, acetyl-CoA may be completely oxidized via the citrate cycle (TCA cycle), which is encoded by the P. sabinae T27 genome (Additional file 1: Figure S1). Although the gene coding for the classical malate dehydrogenase (MDH1, EC:1.1.1.37) in TCA cycle is absent, another malate dehydrogenase (MQO, EC:1.1.5.4) gene which might be involved in pyruvate metabolism pathway metabolizing oxaloacetate to malate, is found in the genome of $P$. sabinae T27.

Sucrose is the common carbon source used for isolation of P. sabinae T27 [13]. The genome of the bacterium has the sucrose-6-phosphate hydrolase and alphaglucosidase for metabolizing sucrose to glucose and fructose. Transporter systems are an important element for bacteria to communicate with their environment. The genome of $P$. sabinae T27 contains an extensive set

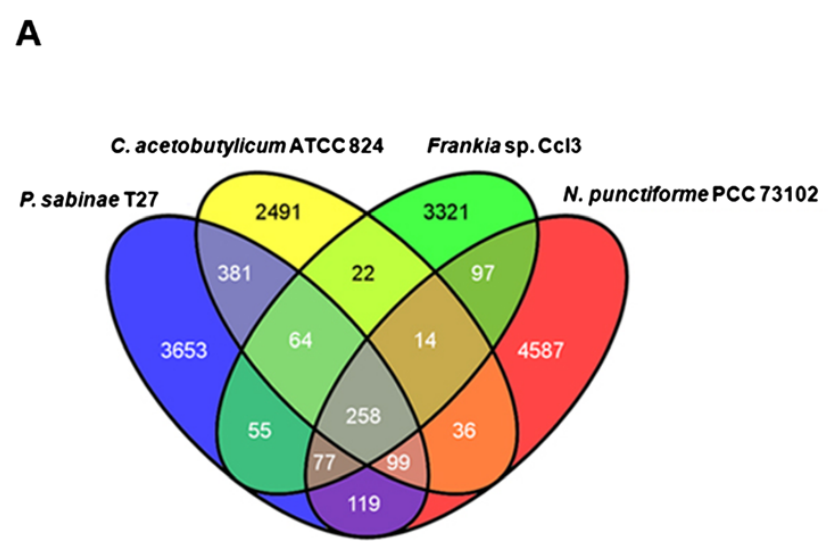

B

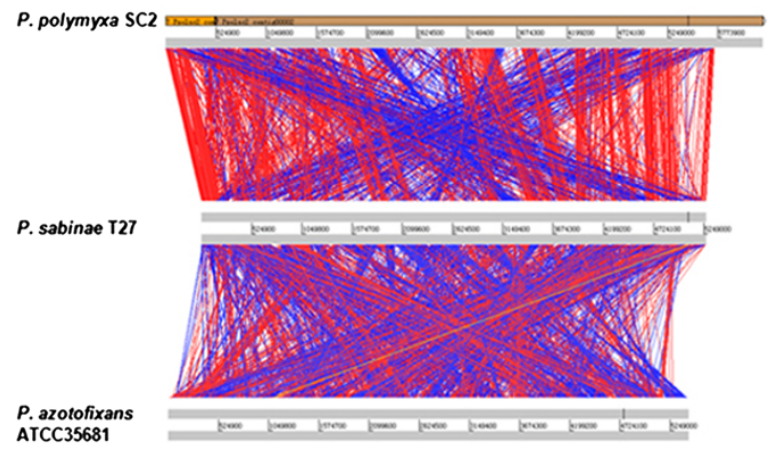

Figure 1 Comparative analysis of the complete genome sequence of $P$. sabinae T27. (A) Alignment of the chromosomes from $P$. sabinae T27, P. azotofixans ATCC35681 and P. polymyxa SC2, generated using the Artemis Comparison Tool. The gray bands located at the top, middle and bottom represent the forward and reverse DNA strands for the chromosome sequences. The red lines correspond to regions of similarity between two chromosomes. The blue lines correspond to regions of rearrangement and recombination between two chromosomes. White regions are those that are unique to one strain. (B) Venn diagram depicting the shared genes which were present in all the $P$. sabinae T27, C. acetobutylicum ATCC 824, Frankia sp. CCl3 and N. punctiforme PCC 73102 and the specific genes which were present and absent from all the four species, and vice-versa. 
of 247 transport related genes. Of the 247 transport related genes, 64 are involved in carbohydrate transport, 66 encode components of amino acid transporters and 107 encode components of inorganic ion transporters. Importantly, Fe (iron), molybdenum, sulfate and $\mathrm{NH}_{4}^{+}$ are related to nitrogen fixation and nitrogen metabolism.

\section{Nitrogen fixation and nitrogenase-like genes}

One of the most distinct features of $P$. sabinae T27 is its ability to fix nitrogen. The genome of $P$. sabinae T27 contains fifteen nif genes, including four nifB, three nifH, one nifD, one nifK, two nifE, two nif $N$, one nif $X$ and one $n i f V$. Of the 15 nif genes, eight nif genes (nifB, nifH, nifD, nifK, nifE, nif $N$, nif $X$ and nifV) and two non-nif genes (orf1 and hesA) which are located between nifX and nif $V$ form a complete nif gene cluster, the four nif genes (nifE, nif $N$, nifB and nifH) are clustered together and the other three nif genes (two nifB and one nifH) are scattered at different locations (Figure 2). In addition to the nif genes, there are nitrogenase-like genes, including two nifH-like and five pairs of nifDK-like genes. Our results are consistent with the reports that nifHDK-like genes existed in Archaea and Firmicutes [8]. Interestingly, genome of $P$. sabinae T27 does not contain transcription regulatory gene nifA which is found in almost all of Gram-negative diazotrophs, such as in K. pneumoniae, A. vinelandii and Pseudomonas stutzeri A1501 [16]. The lack of nifA suggests that there may be a different regulation mechanism of nitrogen fixation in P. sabinae T27.

The content and organization of the complete nif gene cluster Bioinformatics analysis revealed that the ten genes nifBHDKENXorf1hesAnifV within the complete nif gene cluster are organized as an operon within an $11 \mathrm{~kb}$ region. The gene designated as hes $A$ is also found in Frankia [17] and cyanobacteria [18]. The orf1, whose predicted product is a hypothetical protein, is also found in several $\mathrm{N}_{2}$-fixing Paenibacillus species [19]. The predicted product of HesA shares $~ 45 \%$ identity with the putative molybdenum cofactor biosynthesis protein HesA. HesA is a member of the ThiF-MoeB-HesA family and contains an $\mathrm{N}$-terminal nucleotide binding domain and a C-terminal MoeZ/MoeB-like domain. The gene content and organization of the complete nif gene cluster is unique to Paenibacillus $[19,20]$. Although Paenibacillus and Clostridium are the members of the Firmicute, their nif gene content and organization varied greatly. For example, nif $N-B$ fusion gene was found in the nif gene clusters of the three species of Clostridia: C. acetobutylicum, C. beijerinckii, and C. pasteurianum. Also, there are two genes nifI1 and nifI2 located between nifH and nifDK in C. acetobutylicum and C. beijerinckii [21]. Previous studies demonstrated that nifI1 and nifI2 are not essential for nitrogen fixation, but serve a regulatory function [22]. Actually, the nif gene content and organization of Clostridium spp. are more similar to those of Methanosarcina acetovorans and Methanococcus maripaudis, since two genes nifI1 and nifI2 also exist between nifH and nifDK in these archaea.

\section{IS may play important roles in the evolution of the nif and nif-like genes}

As described above, twenty eight insertion sequence (IS) elements, belonging to six transposase families were identified in $P$. sabinae T27 chromosome. IS elements were found to be located on the flanking region of the

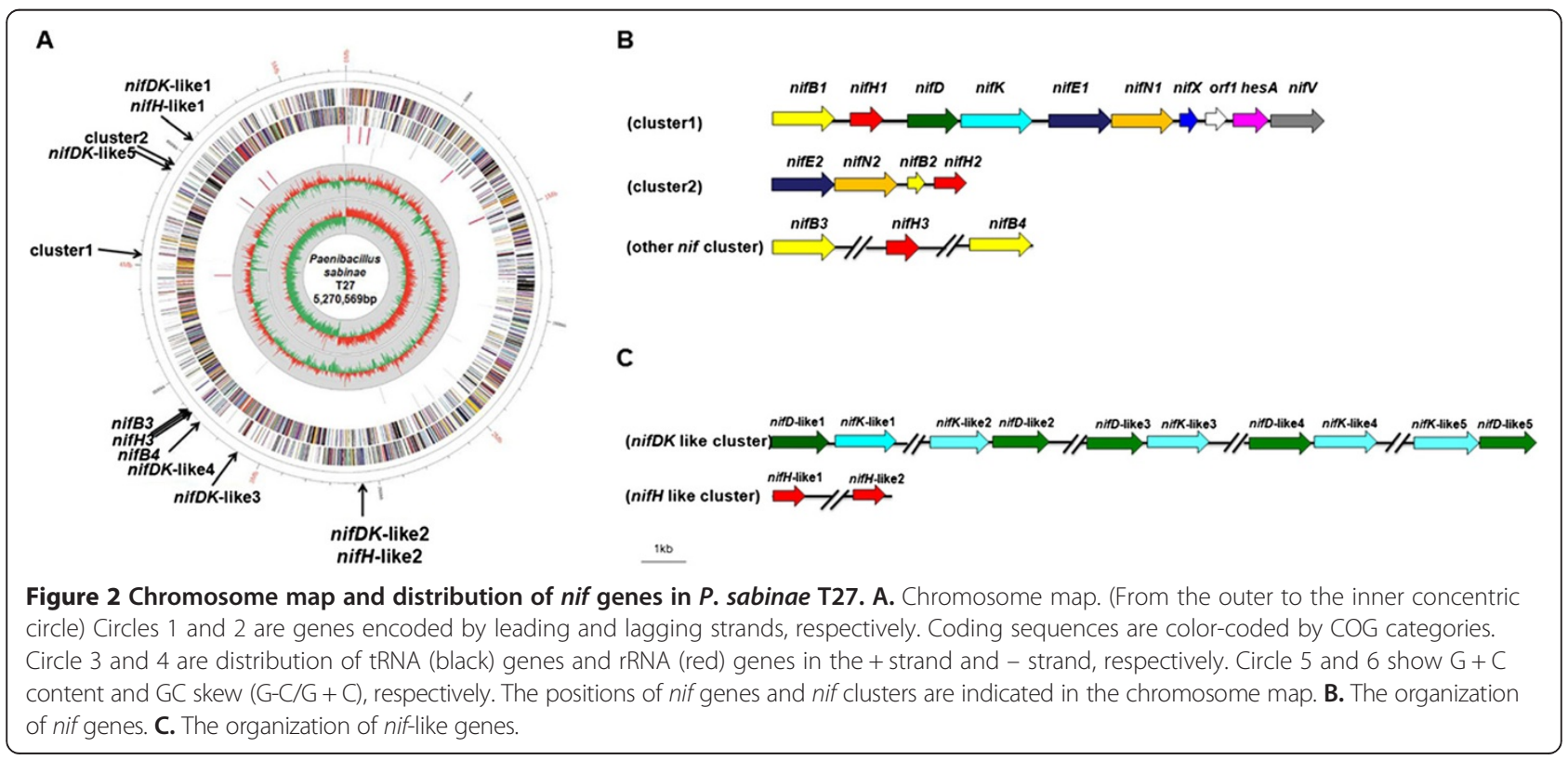


complete nif gene cluster, other nif genes and nif-like genes (Figure 3). It is generally accepted that IS abundance correlates positively with the frequency of horizontal gene transfer (HGT) [23]. IS elements can mediate the transfer of genetic information (such as antibiotic resistance and new metabolic capabilities) between genomes or between replicons of the same genome and they can also induce duplications, deletions, and rearrangements of genetic information [24]. The existence of transposase in the flanking region of the complete nif gene cluster suggests that the nif cluster might be acquired in P. sabinae T27 by HGT event from other diazotrophs and the additional nifBHEN genes and nifHDK-like genes might be horizontally transferred or duplicated. The nif genes acquired by HGT were also reported in several diazotrophs. For example, A sequence reminiscent of a transposase gene located just upstream the nif cluster in Herbaspirillum seropedicae is an indicative of HGT event [25]. It was generally recognized that variations of $\mathrm{G}+\mathrm{C}$ contents between nif cluster and genome are indicative of HGT. For example, $\mathrm{G}+\mathrm{C}$ content of the nif gene cluster was higher than the average of the entire genome $(66.8 \%$ vs. 63.8\%) in P. stutzeri A1501 [16]. However, we found that the $\mathrm{G}+\mathrm{C}$ contents of the complete nif gene cluster of P. sabinae T27 is as same as the average of the entire genome (52.64\% vs. $52.63 \%$ ), suggesting that the complete nif gene cluster of $P$. sabinae T27 has undergone a longer time of evolution.

\section{Evolution of nif and nif-like genes of $P$. sabinae T27}

To further evaluate the evolution of nitrogen fixation in $P$. sabinae T27, we reconstructed the phylogenies based on the concatenation of the NifBHDKENXV sequences (Figure 4). Notably, the Nif protein sequences of P. sabinae T27 used for the phylogenetic trees were from the complete nif cluster. The phylogenetic tree showed that Paenibacillus and Frankia are sister groups, suggesting that $P$. sabinae T27 may originate from a common ancestor with Frankia. Also, we constructed the phylogenetic trees based on the HesA and Orf1 sequences which are contained within the complete nif gene cluster. The HesA phylogenetic tree revealed supported that Paenibacillus and Frankia are sister groups (Additional file 2: Figure S5). The Orf1 phylogenetic tree showed that P. sabinae T27 is closely related to Clostridium (Additional file 3: Figure S6). IS element on the flanking region of the complete nif cluster suggested that the complete nif cluster may have been acquired in P. sabinae T27 by HGT. Interestingly, these data revealed that although Paenibacillus and Clostridium are the members of the Firmicutes, their nif genes are not very closely related.

The complete genome sequence revealed that there are three nifH, one nifD, two nifH-like, five pairs of nifDK-like genes in P. sabinae T27. Here we constructed phylogenetic trees with real NifH/NifD/NifK and NifH/ NifD/NifK-like sequences (Figure 5) and the phylogenetic tree revealed that $\mathrm{NifH} / \mathrm{NifD} / \mathrm{NifK}$-like sequences are clearly divergent from conventional nitrogenase. All NifH-like, NifD-like and NifK-like sequences are clustered together by themselves, suggesting that they may have been resulted from duplication.

As described above, in addition to the ten genes nifBHDKENXorf1hesAnifV within the complete nif gene cluster, three nifB, two nifH, one nifE and one nif $N$ genes exist in the genome of $P$. sabinae T27. Here we further constructed NifB, NifH and the concatenated NifEN phylogenetic trees (Additional files 4, 5, 6: Figures S2-S4) and phylogenetic analysis revealed that these multiple nifB, nifH and nifEN are clustered with their own corresponding genes within the complete nif gene cluster,

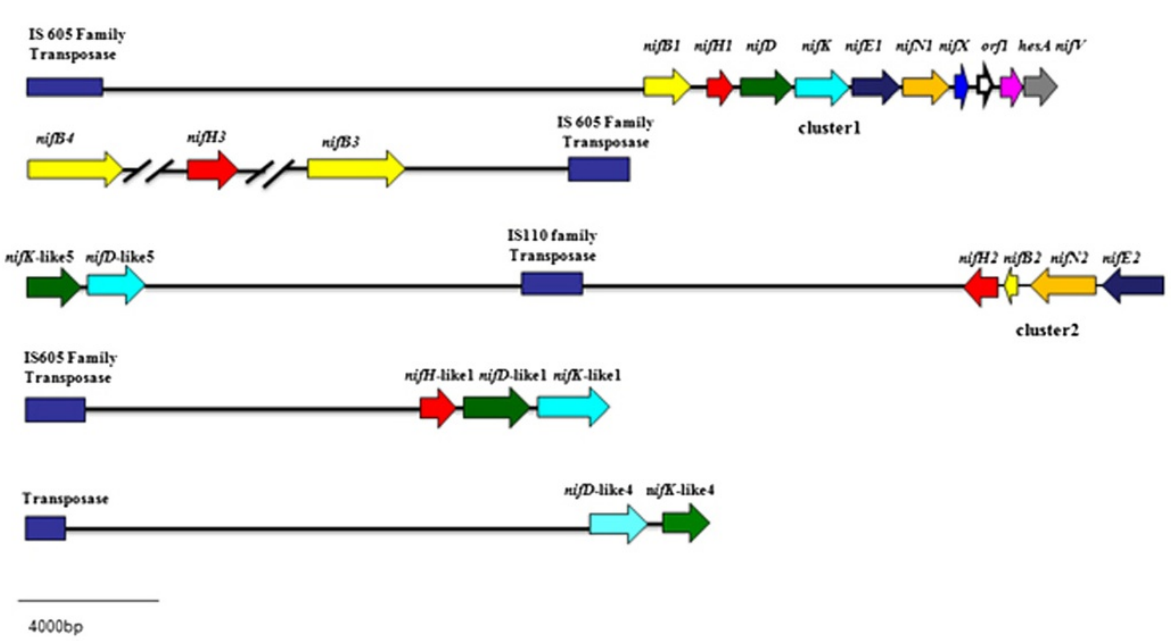

Figure 3 nif and nif-like genes linked to transposonal elements. 


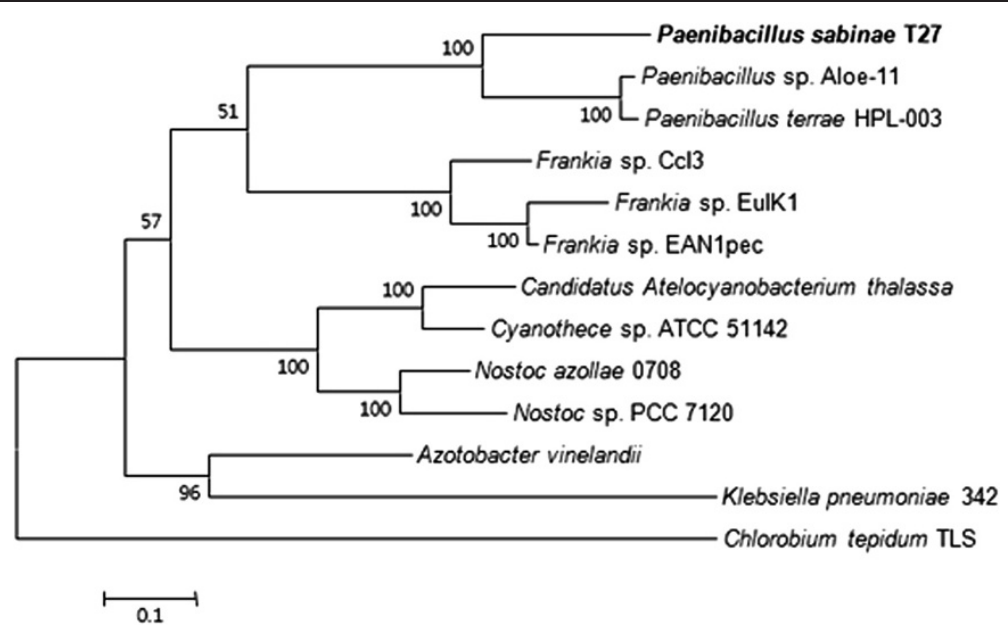

Figure 4 Maximum-likelihood tree based on NifBHDKENXV protein sequences of $P$. sabinae T27 and the representative microorganisms. The numbers at the nodes indicate levels of bootstrap support (\%) based on a neighbor-joining analysis of 100 resampled datasets; only values at or above $50 \%$ are given, Bar 0.1 substitutions per amino acid position.

suggesting that they may result from duplication of nifB, nifH, nifE and nifN, respectively, of the complete nif gene cluster.

\section{Characterization of multiple nitrogenase-like genes}

The nifHDK are structural genes of Mo-nitrogenase, with the nifD and nifK genes encoding the $\alpha$ and $\beta$ subunits, respectively, of the molybdenum iron protein (dinitrogenase) and the nifH the $\gamma$ subunit of the iron protein (dinitrogenase reductase). The genome of $P$. sabinae T27 contains two nifH-like, five nifD-like and five nifK-like genes. Conserved residues in alignments of NifH-like sequences (Figure 6) with NifH sequences show that $4 \mathrm{Fe}-4 \mathrm{~S}$ iron sulfur cluster-ligating cysteines

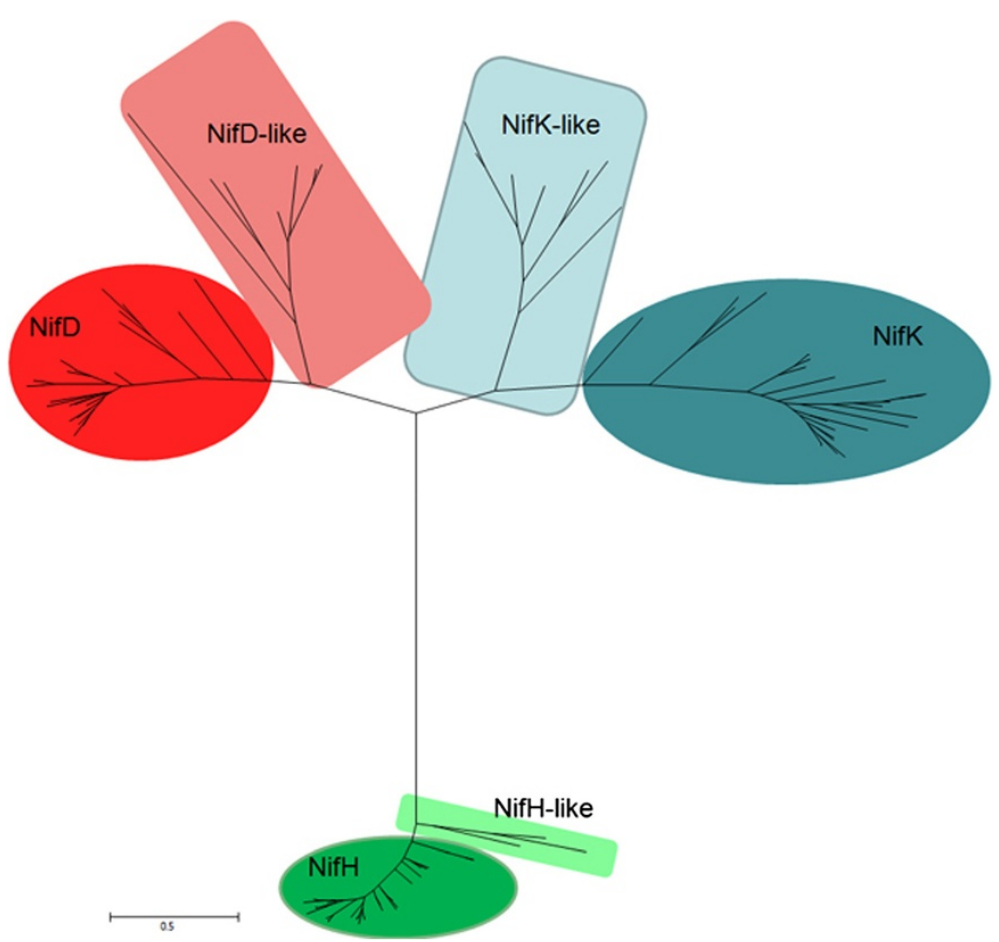

Figure 5 Maximum-likelihood phylogenetic tree of NifHDK/NifHDK-like sequences. NifHDK/NifHDK-like sequences were derived from P. sabinae T27 and the representative microorganisms. The numbers at the nodes indicate levels of bootstrap support (\%) based on a neighborjoining analysis of 100 resampled datasets; only values at or above 50\% are given, Bar 0.1 substitutions per amino acid position. 


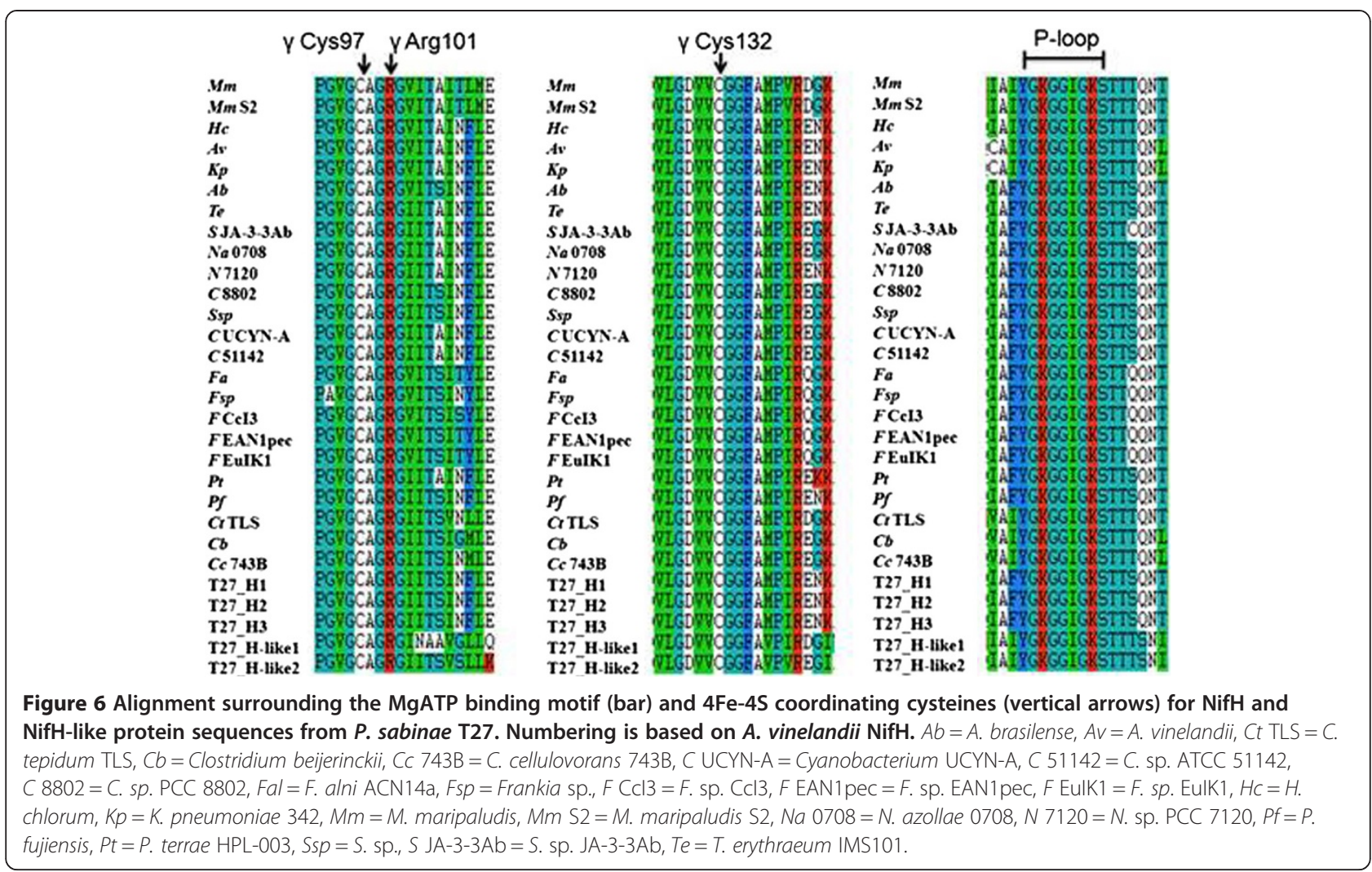

and the P-loop/MgATP binding motif are invariant, suggesting that these proteins may function analogously to dinitrogenase reductase. Conversely, NifD/NifK-like sequences are highly diverged from both the nitrogenase subunits. FeMoco-ligating residues at $\alpha$ Cys 275 and $\alpha$ His442 of NifD (Figures 7, 8) are not conserved in NifD/ NifK-like sequences, although several-but not allconserved cysteines involved with P-cluster coordination are found in NifD/Nifk-like sequences.

\section{Expressions of nifHDK and nifHDK-like genes in $\mathrm{N}_{2}$-fixing and non- $\mathrm{N}_{2}$-fixing conditions}

It is generally recognized that nif genes are expressed in $\mathrm{N}_{2}$-fixing conditions (the microaerobic or anaerobic and without ammonium or limited ammonium). In order to examine whether the transcription of nifHDK and nifHDK-like genes is regulated by ammonium and oxygen in Paenibacillus, expression levels of the P. sabinae T27 nifH, nifD, nifK, nifH-like, nifD-like and nifK-like genes were detected by the real-time quantitative RTPCR method using RNA isolated from cells grown under $\mathrm{N}_{2}$-fxing and non- $\mathrm{N}_{2}$-fxing conditions. As shown in Figure 9, a large (200-1300 fold) increase in the transcript levels of the nifH, nifD and nifK genes was observed in $\mathrm{N}_{2}$ fixing conditions compared to those in the non- $\mathrm{N}_{2}$ fixing conditions. Especially, nifH1, nifD1 and nifK1 within the complete nif cluster were significantly expressed in $\mathrm{N}_{2}$-fixing conditions compared to those in the non- $\mathrm{N}_{2}$ fixing conditions. The data are consistent with the previous reports that the transcription of nifHDK genes is regulated by ammonium and oxygen in $\mathrm{N}_{2}$-fixing organisms, suggesting that the nifHDK genes of $P$. sabinae T27 are involved in nitrogen fixation. In contrast to nifHDK, nifHDK-like genes of $P$. sabinae T27 were not significantly differently expressed in $\mathrm{N}_{2}$-fixing and non- $\mathrm{N}_{2}$-fixing conditions, suggesting that these nif-like genes did not function in nitrogen fixation.

\section{Functional analysis of nifH/nifH-like and nifD/nifD-like genes in nitrogen fixation}

To further comparatively study the functions of the nif and nif-like gene of P. sabinae T27, K. pneumonia nifH mutant strain 1795 and nifD mutant strain I $\alpha 423 \mathrm{P}$ [26], both of which have no or very low nitrogenase activity, were complemented with the nifH/nifH-like and nifD/ nifD-like genes of $P$. sabinae T27 under the control of K. pneumonia nifH promoter, respectively. As shown in Figure $10 \mathrm{~A}$, the complementary strains carrying nifHlike1 or nifH-like2 of $P$. sabinae T27 could not resumed the nitrogenase activity of $K$. pneumonia nifH mutant strain 1795, while the nifH1 from the complete nif cluster of P. sabinae T27 could restore to nearly $50 \%$ of the 

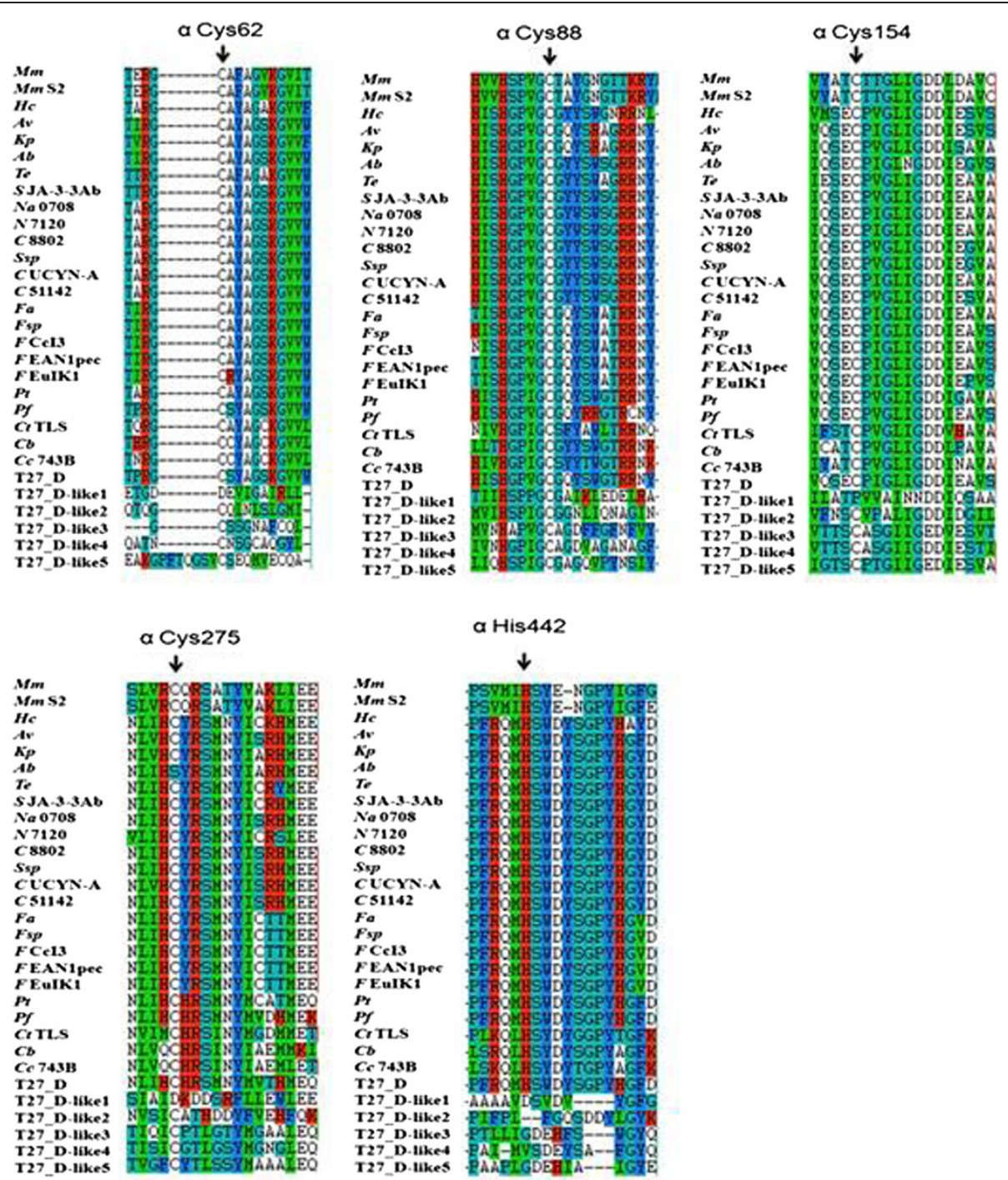

Figure 7 Conservation in and around crucial residues (FeMo-co and P-cluster ligands) in NifD and NifD-like protein sequences from $P$. sabinae The P-cluster and FeMo-co ligands, based on $A$ vinelandii numbering, are indicated with vertical arrows. $A b=A$. brasilense, $A v=A$. vinelandii, $C t T L S=C$. tepidum $T L S, C b=C$ lostridium beijerinckii, CC 743B $=$ C. cellulovorans 743B, C UCYN-A = Cyanobacterium UCYN-A, C

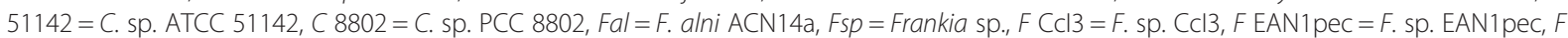
EulK1 = F. sp. EulK1, Hc = H.chlorum, Kp=K. pneumoniae 342, Mm = M. maripaludis, Mm S2 = M. maripaludis S2, Na 0708=N. azollae 0708, $N 7120=N$. sp. PCC 7120, Pf = P. fujiensis, Pt = P. terrae HPL-003, Ssp =S. sp., S JA-3-3Ab =S. sp. JA-3-3Ab, Te= T. erythraeum IMS101.

wild-type strain M5al. The data are consistent with our previous report that the three copies of nifH could restore nitrogenase activity of $K$. pneumonia nifH ${ }^{-}$mutant strain 1795 [27]. Likewise, nifD of P. sabinae T27 could resumed the nitrogenase activity of $K$. pneumonia nifD $D^{-}$ mutant strain I $\alpha 423$, although $K$. pneumonia nifD enabled $K$. pneumonia nifD $D^{-}$mutant strain I $\alpha 423 P$ to have higher nitrogenase activity than P. sabinae T27 nifD did (Figure 10B). In contrast, none of nifD-like1, nifD-like2, nifD-like3, nifD-like4 and nifD-like5 could restore the nitrogenase activity of $K$. pneumonia nif $D^{-}$mutant. These data suggest that nif-like genes may be not involved in nitrogen fixation.

The complete nif gene cluster is organized as an operon Bioinformatics analysis revealed that the ten genes nifBHDKENXorf1hesAnifV within the complete nif gene cluster are organized as an operon. Here RT-PCR experiments using primers designed to span across intergenic regions indicated that the nine genes within the nif cluster are organized in a single operon (Additional file 7: Figure S7). Single operon nif clusters have been reported 


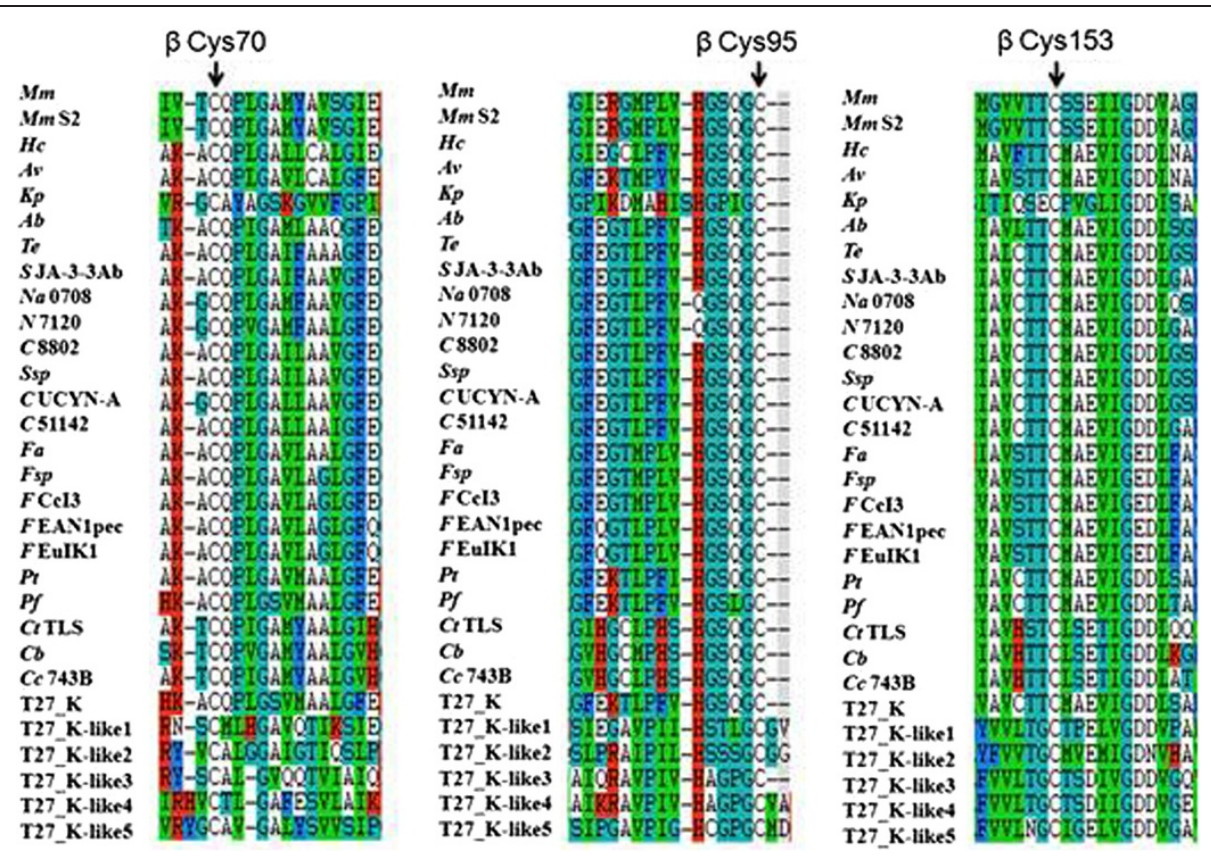

Figure 8 Conservation in and around crucial residues (P-cluster ligands) in NifK and NifK-like protein sequences from P. sabinae T27. The P-cluster ligands based on $A$. vinelandii numbering, are indicated with vertical arrows. $A b=A$. brasilense, $A v=A$. vinelandii, $C t T L S=C$. tepidum TLS, Cb = Clostridium beijerinckii, CC 743B = C. cellulovorans 743B, C UCYN-A = Cyanobacterium UCYN-A, C 51142 = C. sp. ATCC 51142,

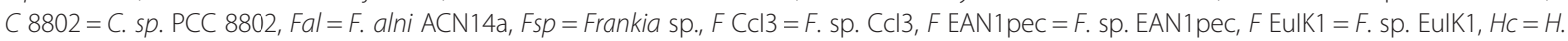
chlorum, $K p=K$. pneumoniae $342, M m=M$. maripaludis, Mm S2 $=$ M. maripaludis $S 2$, Na $0708=N$. azollae 0708, N 7120 = N. $s p . P C C 7120, P f=P$. fujiensis, $P t=P$. terrae HPL-003, Ssp =S. sp., S JA-3-3Ab =S. sp. JA-3-3Ab, Te $=$ T. erythraeum IMS101.

in gram-positive prokaryotes and in the archaea, e.g. Heliobacterium chlorum [28] and Methanococcus maripaludis [29]. However, in contrast to these nif clusters P. sabinae T27 does not contain the negative regulatory genes nifI1 and nifI2 (homologues of $g \ln B$ ), which are involved in post-translational regulation of nitrogenase activity in response to fixed nitrogen [30].

The complete nif gene cluster of $P$. sabinae T27 has a $\sigma^{70}$ dependent promoter

Almost all of the nif genes in Gram-negative nitrogenfixing bacteria, such as $K$. pneumoniae and $A$. vinelandii, are transcribed from $\sigma^{54}$ promoters $(-24 /-12)$ whose expression depends on activator NifA [31]. However, the presumed promoter regions for the nif genes of $P$. sabinae T27 have sequences which are similar to the E. coli $\sigma^{70}$ dependent -35 and -10 consensus promoter. The following experiments demonstrated that the nif promoter of P. sabinae T27 is distinct from those of those of Gramnegative nitrogen-fixing bacteria.

The transcriptional start site (TSS) of the nif gene cluster in P. sabinae T27 was determined by using the 5 '-RACE (Rapid Amplification of cDNA Ends) method. The TSS was located 222 bp upstream of the translational start site of nifB and a putative promoter was identified 6 nucleotides preceding the TSS (Additional file 8: Figure S8A). The -35 (TTGACG) and -10 (TATGAT) sequences in the nifB promoter were similar to the corresponding consensus sequences (TTGACA and TATAAT respectively) of $E$. coli $\sigma^{70}$-dependent promoters. A $\sigma^{54}$-dependent $-24 /-12$ promoter sequence was not observed upstream of the nif cluster. Downstream of nifV, a potential transcriptional termination site was identified, containing two potential stem loops followed by a T-rich region (Additional file 8: Figure S8A). These findings indicate that the nif genes in $P$. sabinae T27 are organized as a single operon containing 9 genes, which is transcribed from an rpoD-dependent promoter.

To analyze the $\sigma^{70}$-dependentcy of the nifB promoter, electrophoretic mobility shift assays (EMSA) were carried out using either $E$. coli $\sigma^{70}$-RNAP (RNA polymerase) or $\sigma^{70}$ from $P$. sabinae T27, which was overexpressed and purified from E. coli (Additional file 8: Figure S8B). EMSA experiments revealed that both purified $\sigma^{70}$ from P. sabinae T27 and E. coli $\sigma^{70}$-RNAP holoenzyme bind to the 45 bp nifB promoter fragment. Competition experiments with non-labelled nifB DNA indicated that the $E$. coli RNAP holoenzyme binds more tightly to this DNA fragment, since higher concentrations of competitor were apparently required to dissociate the E. coli $\sigma^{70}$-RNAP 


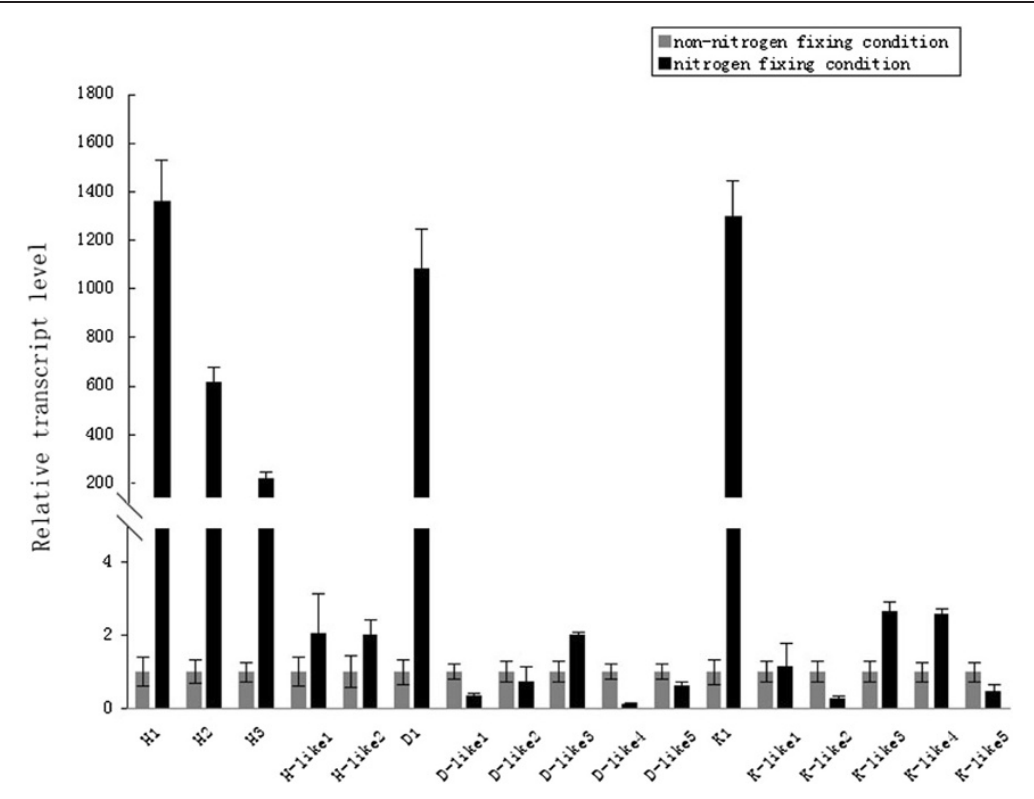

Figure 9 Quantitative real-time RT-PCR analysis of transcripts of nifHDK and nifHDK-like genes of $P$. sabinae T27.

(Additional file 8: Figure S8C and D). These results are consistent with the ability of $\sigma^{\mathrm{A}}\left(\sigma^{70}\right)$ of Bacillus subtilis to bind to promoters independent of core RNAP [32,33].

The complete nif gene cluster of $P$. sabinae T27 enables E. coli to fix nitrogen

We further cloned the 12-kb full-length nif gene cluster consisting of its own nif promoter and the contiguous nine genes nifBHDKENXorf1hesAnifV into the wide-host plasmid pVK100 and then transformed this into E. coli JM109, yielding the recombinant $E$. coli strain 27 (Additional file 9: Figure S9). To determine whether the Paenibacillus nif gene cluster functions in E. coli, we employed two independent methods to assess nitrogenase activity: firstly, reduction of the alternative substrate acetylene to ethylene, which can be readily quantified by gas chromatography [34,35] and secondly, a ${ }^{15} \mathrm{~N}_{2}$ enrichment assay to directly measure the incorporation of this tracer into organic nitrogen [36]. When grown anaerobically in nitrogen-deficient medium, $P$. sabinae T27 exhibits both acetylene reduction and ${ }^{15} \mathrm{~N}_{2}$ incorporation (Additional file 9: Figure S9). The recombinant E. coli strain 27, which expresses the nif genes from the native promoter showed approximately $10 \%$ of the specific activity for acetylene
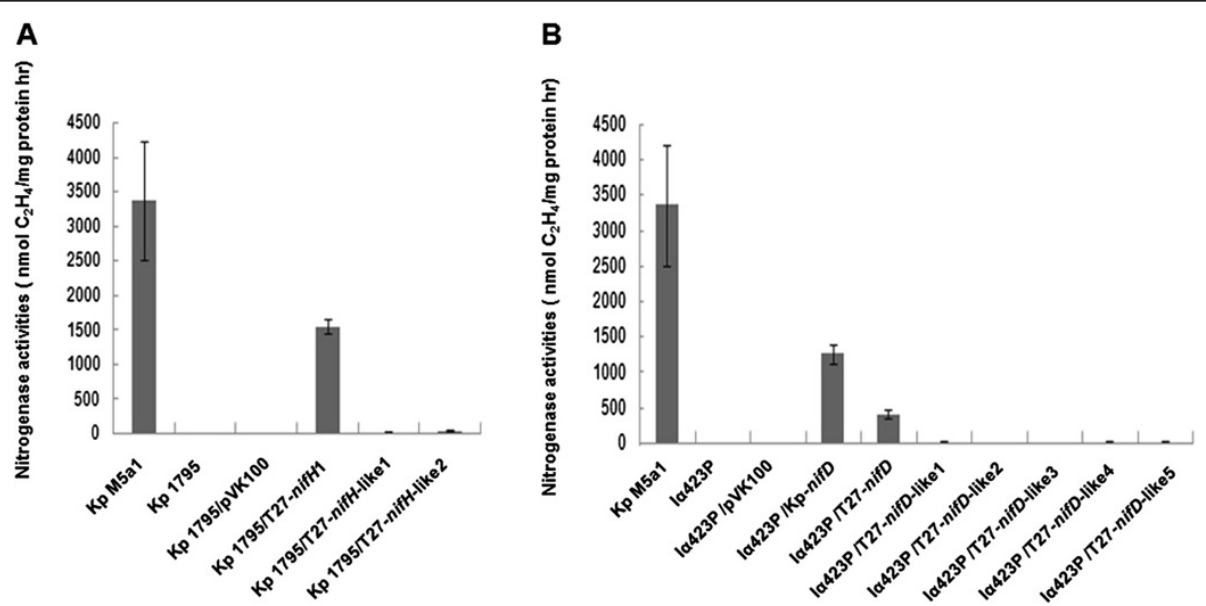

Figure 10 The nitrogenase activities of complementary strains and control strains. Kp M5a1: Wild-type K. pneumonia; Kp1795: K. pneumonia nifH mutant strain; la423P: K. pneumonia nifD mutant strain. (A) Complementation by nifH/nifH-like genes. (B) Complementation by nifD/nifD-like genes. 
reduction when compared with Paenibacillus and was competent to assimilate ${ }^{15} \mathrm{~N}_{2}$. The results demonstrated that the complete nif gene cluster is a functional unit.

\section{Conclusions}

In this study, we uncovered the contents and organization of nif and nif-like genes of $P$. sabinae T27 by completing its genome sequence. The genome of $P$. sabinae T27 contains fifteen nitrogen fixation (nif) genes, including three nifH, one nifD, one nifK, four nifB, two nifE, two nifN, one nif $X$ and one nif $V$. Of the 15 nif genes, eight nif genes (nifB, nifH, nifD, nifK, nifE, nifN, nif $X$ and nifV) and two non-nif genes (orf1 and hesA) form a complete nif gene cluster. Phylogenetic analysis suggests that the complete nif cluster of $P$. sabinae T27 was originated from a common ancestor with Frankia. Multiple nifB, nifH, nifE, nifN may result from duplication. The complete nif gene cluster is organized in an operon as a functional unit for nitrogen fixation. The complete nif gene cluster under the control of its $\sigma^{70}$-dependent promoter enabled Escherichia coli JM109 to fix nitrogen. P. sabinae T27 contains two nifH-like genes and five pairs of nifDK-like genes. Unlike nif genes, the transcriptions of nifHDK-like genes were not regulated by ammonium and oxygen and nifHDK-like genes were not involved in nitrogen fixation.

\section{Methods}

\section{Strains and media}

Strains used in this study is listed in Additional file 10: Table S1. P. sabinae T27 and the recombinant E. coli strains were routinely grown in LD medium (per liter contains: $2.5 \mathrm{~g} \mathrm{NaCl}, 5 \mathrm{~g}$ yeast and $10 \mathrm{~g}$ tryptone) at $30^{\circ} \mathrm{C}$ with shaking. When appropriate, antibiotics were added in the following concentrations: $100 \mu \mathrm{g} / \mathrm{ml}$ ampicillin, and $20 \mu \mathrm{g} / \mathrm{ml}$ tetracycline for maintenance of plasmids.

Nitrogen-free and nitrogen-deficient media were used in this study. Nitrogen-free medium contained (per liter) 10.4 $\mathrm{g} \mathrm{Na}_{2} \mathrm{HPO}_{4}, 3.4 \mathrm{~g} \mathrm{KH}_{2} \mathrm{PO}_{4}, 26 \mathrm{mg} \mathrm{CaCl} \cdot 2 \mathrm{H}_{2} \mathrm{O}$, $30 \mathrm{mg} \mathrm{MgSO}_{4}, 0.3 \mathrm{mg} \mathrm{MnSO}_{4}, 36 \mathrm{mg}$ Ferric citrate, $7.6 \mathrm{mg} \mathrm{Na} \mathrm{MoO}_{4} \cdot 2 \mathrm{H}_{2} \mathrm{O}, 10 \mu \mathrm{g}$ p-aminobenzoic acid, $5 \mu \mathrm{g}$ biotin and $4 \mathrm{~g}$ glucose as carbon source. Nitrogendeficient medium contained $2 \mathrm{mM}$ glutamate as nitrogen source in nitrogen-free medium [20].

\section{Phylogenetic analysis}

Maximum-likelihood (ML) phylogenetic trees were constructed using PhyML (version 3.0) [37] software and multiple alignment of amino acid sequences were carried out by ClustalW (version 2.1) [38].

\section{Genome sequencing, genome annotation and analysis}

Genomic DNA of P. sabinae T27 was isolated according to [13]. Genome sequencing was performed by Tianjin Research Center for Functional Genomics and Biochip in China. The genome P. sabinae T27 was sequenced by using a hybrid sequencing approach that incorporates 454 pyrosequencing with Illumina Genome Analyzer. Sequencing by both methods was performed according to manufacturer's instructions, Roche and Illumina.

The rRNA genes were identified with RNAmmer [39]. Transfer RNA (tRNA) genes were identified by the program tRNAscan-SE [40]. Genes coding for proteins with known functions were annotated by searches against KEGG Genes, Pfam, and SWISSPROT [41]. The complete sequence has been assigned GenBank accession no. СР004078.

\section{Construction of recombinant plasmid for expression of the complete nif cluster in $E$. coli}

Genomic DNA of P. sabinae T27 was used as template for cloning nif genes. A $12 \mathrm{~kb}$ Xho I-Xho I DNA fragment containing the complete nif gene cluster (a 310 bp promoter region and the contiguous ten genes nifBHDKENXorflhesAnifV and 194 bp downstream of the stop codon TAA of nifV) was PCR amplified with primers T-up and T-down (Additional file 11: Table S2). The PCR product was ligated to Xho I site of pVK100, yielding plasmid pKY100-27. Then the plasmid was transferred to $E$. coli JM109, yielding the recombinant $E$. coli 27 strain.

\section{Construction of plasmids for complementation studies}

In order to determine the function of nifH/nifH-like and nifD/nifD-like genes, overlap PCR was performed to fuse the coding regions of nifH1, nifH-like1, nifH-like2, nifD, nifD-like1, nifD-like2, nifD-like3, nifD-like4 and nifDlike5 of $P$. sabinae T27 with the nifH promoter of $K$. pneumoniae. The primers used in fusion were listed in Additional file 11: Table S2. The amplified PCR products were cloned to pVK100. The recombinant pVK100 were transformed to K. pneumoniae nifH mutant or K. pneumoniae nifD mutant for complementation.

\section{Transcription start site identification}

The 5'-RACE method was used to determine the transcription start site (TSS) using the SMARTer ${ }^{\text {rn }}$ RACE cDNA Amplification Kit (Clontech). Gene-specific primers are listed in Additional file 11: Table S2. The PCR product was cloned into the pMD18-T Vector and then sequenced.

\section{Overexpression and purification of $\sigma^{70}$ from $P$. sabinae T27 in E. coli}

A 1134 bp DNA fragment carrying the rpoD gene (encoding $\sigma^{70}$ of P. sabinae T27) was PCR amplified with primers sigma A-F and sigma A-R (Additional file 11: Table S2). The PCR product was ligated to the pET-28b expression vector, yielding plasmid pET28- $\sigma^{70}$. E. coli strain BL21 (DE3) was transformed with expression plasmid pET28- $\sigma^{70}$ and utilized for protein expression. The bacterial cells were grown in LB medium to the end of 
$\log$ phase and then a final concentration of $1 \mathrm{mM}$ IPTG (isopropyl- $\beta$-D-thiogalactopyranoside) was added to the culture and the cells were harvested after incubation for another $4 \mathrm{~h}$ at $16^{\circ} \mathrm{C}$. The cells were then harvested and disrupted by sonication on ice. The protein was purified from the supernatant with $\mathrm{Ni}^{2+}$-NTA agarose (Qiagen) according to the manufacturer's instructions.

\section{Electrophoretic mobility shift assay (EMSA)}

For the electrophoretic mobility shift assay (EMSA), a $50 \mathrm{bp}$ nif promoter fragment (from -47 to +3 relative to the transcription start site of nifB in P. sabinae T27) was synthesized by Sangon Biotech Co., Ltd (Shanghai). To do this, two DNA fragments corresponding to the sequences of the first strand (5' - GGAGAAGTGAATTGACTGTA TTTGTCCCTGTCTCTAAGA-TGTAATTATAT-3') and the complementary DNA strand (5' - ATATAATTACATC TTAGAGAC-AGGGACAAATACAGTCAATTCACTTC TCC-3') were synthesized. The two strands were annealed and then labeled with digoxin using the DIG Gel Shift Kit (Roche). The binding shift experiment of E. coli $\sigma^{70}$-RNAP (RNA polymerase) (Epicentre) or $\sigma^{70}$ of $P$. sabinae T27 to the nif promoter was carried out using a gel shift kit (Roche). At the same time, a scrambled 39 bp DNA fragment formed by annealing the following complementary oligonucleotides (5' - GTACGGAGTATCCAGCTCCGTA GCATGCAAATCCTCTGG-3') and (5'-CCAGAGGATT TGCATGCTACGGAGCTGGATACTCCGTAC -3') was used to assay non-specific binding.

\section{RT-PCR and qRT-PCR analysis}

For RT-PCR, $P$. sabinae $\mathrm{T} 27$ was grown in $\mathrm{N}_{2}$-fixing conditions (without $\mathrm{NH}_{4} \mathrm{Cl}$ and $\mathrm{O}_{2}$ ). For qRT-PCR, P. sabinae T27 was grown in $\mathrm{N}_{2}$-fixing conditions (without $\mathrm{NH}_{4} \mathrm{Cl}$ and $\mathrm{O}_{2}$ ) and non- $\mathrm{N}_{2}$-fixing conditions $(100 \mathrm{mM}$ ammonium and $21 \% \mathrm{O}_{2}$ ). The culture was harvested by centrifugation at $4{ }^{\circ} \mathrm{C}$, and total RNA was isolated using the PrimeScript $^{\ominus}$ RT reagent Kit with gDNA Eraser (Takara Bio) according to the manufacturer's instructions. The possibility of contamination of genomic DNA was eliminated by digestion with RNase-free DNase I (Takara Bio). The integrity and size distribution of the RNA was verified by agarose gel electrophoresis, and the concentration was determined spectrophotometrically. Synthesis of cDNA was carried out using RT Prime Mix according to the manufacturer's specifications (Takara Bio). $0.8 \mu \mathrm{g}$ of cDNA was used for RT-PCR. The nif and nif-like gene transcripts were detected by using an RT-PCR Kit with $16 \mathrm{~S}$ rDNA as a control. Primers for nif, nif-like genes and 16S rDNA used for PCR are listed in (Additional file 11: Table S2).

Nitrogenase activity assays by acetylene reduction method For nitrogenase activity assays, P. sabinae T27 and the recombinant $E$. coli 27 strain were grown in $5 \mathrm{~mL}$ of $\mathrm{LD}$ media (supplemented with antibiotics when necessary) in $50-\mathrm{ml}$ flasks shaken at $250 \mathrm{rpm}$ for $16 \mathrm{~h}$ at $30^{\circ} \mathrm{C}$. Nitrogenase activity assays was performed according to Wang et al's reports [20].

\section{${ }^{15} \mathrm{~N}_{2}$ incorporation assay}

$P$. sabinae T27 and the recombinant $E$. coli strain were grown overnight in LD medium. The cultures were collected and resuspended in $70 \mathrm{ml}$ nitrogen-deficient medium containing $2 \mathrm{mM}$ glutamate as nitrogen source to an $\mathrm{OD}_{600}$ of 0.4 in a $120 \mathrm{ml}$ serum bottle. ${ }^{15} \mathrm{~N}_{2}$ incorporation assay was performed according to Wang et al's report [20].

\section{Additional files}

Additional file 1: Figure S1. Schematic overview of metabolic pathways and transport systems in P. sabinae T27. Predicted transporters are grouped by energy specificity: red, ATP-dependent transporters; deep pink, symporters; light pink, ion channels; yellow, transporter family. Arrows indicate direction of transport. Final biosynthetic products are indicated with orange boxes. Crosses indicate pathways or reactions that are apparently not present in P. sabinae T27.

Additional file 2: Figure S5. Maximum-likelihood tree based on complete HesA protein sequences showing relationships between HesA protein of $P$. sabinae T27 and HesA proteins from representative microorganisms. The numbers at the nodes indicate levels of bootstrap support (\%) based on a neighbor-joining analysis of 100 resampled datasets; only values at or above $50 \%$ are given, Bar 0.1 substitutions per amino acid position.

Additional file 3: Figure S6. Maximum-likelihood tree based on ORF1 sequences showing relationships between ORF1 of $P$. sabinae T27 and ORF1 from representative microorganisms. The numbers at the nodes indicate levels of bootstrap support (\%) based on a neighbor-joining analysis of 100 resampled datasets; only values at or above $50 \%$ are given, Bar 0.1 substitutions per amino acid position.

Additional file 4: Figure S2. Maximum-likelihood tree based on complete NifB protein sequences showing relationships between NifB proteins of $P$. sabinae $T 27$ and NifB proteins from representative microorganisms. The numbers at the nodes indicate levels of bootstrap support (\%) based on a neighbor-joining analysis of 100 resampled datasets; only values at or above $50 \%$ are given, Bar 0.1 substitutions per amino acid position.

Additional file 5: Figure S3. Maximum-likelihood tree based on complete $\mathrm{NifH}$ protein sequences showing relationships between $\mathrm{NifH}$-like proteins of $\mathrm{P}$. sabinae T27 and NifH proteins from representative microorganisms. The numbers at the nodes indicate levels of bootstrap support (\%) based on a maximum-likelihood analysis of 100 resampled datasets; only values at or above $50 \%$ are given, Bar 0.2 substitutions per amino acid position.

Additional file 6: Figure S4 Maximum-likelihood tree based on complete NifEN protein sequences showing relationships between NifEN proteins of $P$. sabinae T27 and NifEN proteins from representative microorganisms. The numbers at the nodes indicate levels of bootstrap support (\%) based on a neighbor-joining analysis of 100 resampled datasets; only values at or above $50 \%$ are given, Bar 0.1 substitutions per amino acid position. Paenibacillus sabinae T27 NifE1N1 (AHV98644, AHV98643), Paenibacillus sabinae T27 NifE2N2 (AHV98966, AHV98965), Cyanobacterium UCYN-A (YP_003421699, YP_003421700), Cyanothece sp. ATCC 51142 (ACB49914, ACB49915), Frankia sp. CCl3 (YP_483560, YP_483559), Nostoc azollae 0708 (YP_003720729, YP_003720728), Nostoc punctiforme PCC 73102 (YP_001869140, YP_001869141), Nostoc sp. PCC 7120 (WP_010995610, WP_010995609), Synechococcus sp. JA-3-3Ab (YP_475248, YP_475249), Azospirillum brasilense (WP_014199505, 
WP_014199506), Azotobacter vinelandii (AAA64716, AAA64717), Chlorobium tepidum TLS (NP_662422, NP_662423), Trichodesium erythraeum IMS101 (YP_723620, YP_723620), Cyanothece sp. PCC 8802 (YP_003137550, YP_003137551), Frankia sp. EulK1 (AAD17262, AAD17263), Frankia sp. EAN1 pec (ABW16212, ABW16211), Frankia alni ACN14a (YP_716936, YP_716935), Heliobacterium chlorum (BAD95756, BAD95757), Klebsiella pneumoniae 342 (YP 002237560, YP 002237559). Methanococcus maripaludis (AAC45517, AAC45518), Paenibacillus terrae HPL-003 (YP 005075595, YP 005075596), Methanococcus maripaludis S2 (NP_987978, NP_987979), Methanococcus vannielii SB (YP_001322586, YP 001322585), Methanothermobacter thermautotrophicus str. Delta H (NP_276678, NP_276679), Paenibacillus sp. Aloe-11 (WP_007429045, WP_007429046), Paenibacillus massiliensis (AAX73208, AAX73209), Rivularia sp. PCC 7116 (YP_007059114, YP_007059113).

Additional file 7: Figure S7. The ten genes nifB1, nifH1, nifD, nifK, nifE1, nifN1, nifX, orf1, hesA and nifl within the complete nif gene cluster of $P$. sabinae T27 are organized in an operon as determined by RT-PCR. (A) Outline of the strategy. Primers used and amplified products (numbered) are given below the schematic representation of the genes. (B) Result of RT-PCR reactions with RNA from $P$. sabinae 27 grown under $\mathrm{N}_{2}$-fixing conditions. The numbering on the top of the gels corresponds to the product numbers drawn schematically in the outline given above. RT, standard RT-PCR reaction; $(-)$, negative control in which no reverse transcriptase was added to the RT reaction; (+), positive control in which genomic DNA was used as template in the RT-PCR.

Additional file 8: Figure S8. Characterization of the nif promoter of P. sabinae T27. (A) Nucleotide sequence of the nifB promoter. (B) Overexpression and purification of $\sigma^{70}$ from Lane 1: protein marker; lane 2: uninduced protein; lane 3: induced protein; lanes 4: purified $\sigma^{70}$ factor. (C) Electrophoretic mobility shift assays (EMSA) demonstrating binding of P. sabinae $\sigma^{70}$ to the $45 \mathrm{bp}$ nifB promoter DNA fragment (final concentration $0.03 \mathrm{pmol}$ ). The protein concentration is indicated in pmol above each lane (left hand panel). In the right hand panel, the protein concentration was maintained at $2.4 \mathrm{pmol}$ and unlabeled nifB promoter fragment was added as competitor (concentration indicated above each lane). (D) EMSA experiments demonstrating binding of $E$. coli $\sigma^{70}$-RNAP to the $45 \mathrm{bp}$ nifB promoter DNA fragment (final concentration 0.03). The protein concentration is indicated in pmol above each lane (left hand panel). In the right hand panel, the protein concentration was maintained at $0.2 \mathrm{pmol}$ and unlabeled nifB promoter fragment was added as competitor (concentration indicated above each lane).

Additional file 9: Figure S9. Nitrogenase activity of E. coli T27, E. coli JM109 and P. sabinae T27. E. coli T27 carrying the complete nif gene cluster from P. sabinae T27. E. coli JM109 carrying the empty vector plasmid pVK100 and $P$. sabinae T27 are used as negative and positive controls, respectively. Strains were grown anaerobically in nitrogen-deficient conditions.

Additional file 10: Table S1. Strains and plasmids used in this research. Additional file 11: Table S2. Primers used in this study.

\section{Competing interests}

The authors declare that they have no competing interests.

\section{Authors' contributions}

Analyzed the data: ZD XL YY ML QC JX TW SC. Prepared figures and tables: XL ZD JX. Conducted experiments: XL ZD ZL. Designed experiments and wrote paper: SC. All authors helped to draft and approved the final manuscript.

\section{Acknowledgements}

This work was supported by funds from the National "973" Project (Grant No. 2010CB126504).

\section{Author details}

"Key Laboratory for Agrobiotechnology, Ministry of Agriculture, China Agricultural University, Beijing 100193, P. R. China. ${ }^{2}$ Key laboratory of Soil Microbiology, Ministry of Agriculture, China Agricultural University, Yuanmingyuan west road no.2, Haidian District, Beijing 100193, P. R. China. ${ }^{3}$ Biotechnology Research Institute, Chinese Academy of Agricultural Sciences, Beijing 100081, P. R. China.
Received: 7 November 2013 Accepted: 31 July 2014

Published: 27 August 2014

\section{References}

1. Falkowski PG: Evolution of the nitrogen cycle and its influence on the biological sequestration of $\mathrm{CO}_{2}$ in the ocean. Nature 1997, 387(6630):272-275.

2. Rubio LM, Ludden PW: Biosynthesis of the iron-molybdenum cofactor of nitrogenase. Annu Rev Microbiol 2008, 62(1):93-111.

3. Hu Y, Ribbe MW: Biosynthesis of nitrogenase FeMoco. Coord Chem Rev 2011, 255(9-10):1218-1224.

4. Arnold W, Rump A, Klipp W, Priefer UB, Pühler A: Nucleotide sequence of a 24,206-base-pair DNA fragment carrying the entire nitrogen fixation gene cluster of Klebsiella pneumoniae. J Mol Biol 1988, 203(3):715-738.

5. Setubal JC, dos Santos P, Goldman BS, Ertesvag H, Espin G, Rubio LM, Valla S, Almeida NF, Balasubramanian D, Cromes L, Curatti L, Zijin D, Godsy E, Goodner B, Burris KH, Hernandez JA, Houmiel K, Imperial J, Kennedy C, Larson TJ, Latreille P, Ligon LS, Lu J, Maerk M, Miller NM, Norton S, Carroll IP, Paulsen I, Raulfs EC, Roemer R, et al: Genome sequence of Azotobacter vinelandii, an obligate aerobe specialized to support diverse anaerobic metabolic processes. J Bacteriol 2009, 191:4534-4545.

6. Michiels J, D'Hooghe I, Verreth C, Pelemans H, Vanderleyden J: Characterization of the Rhizobium leguminosarum biovar phaseoli nifA gene, a positive regulator of nif gene expression. Arch Microbiol 1994, 161(5):404-408.

7. Wang SZ, Chen JS, Johnson JL: The presence of five nifH-like sequences in Clostridium pasteurianum: sequence divergence and transcription properties. Nucleic Acids Res 1988, 16:439-454.

8. Dos Santos P, Fang Z, Mason S, Setubal J, Dixon R: Distribution of nitrogen fixation and nitrogenase-like sequences amongst microbial genomes. BMC Genomics 2012, 13(1):162.

9. Raymond J, Siefert JL, Staples CR, Blankenship RE: The natural history of nitrogen fixation. Mol Biol Evol 2004, 21(3):541-554.

10. Boyd ES, Anbar AD, Miller S, Hamilton TL, Lavin M, Peters JW: A late methanogen origin for molybdenum-dependent nitrogenase. Geobiology 2011, 9(3):221-232

11. Ash C, Priest F, Collins MD: Molecular identification of rRNA group 3 bacilli (Ash, Farrow, Wallbanks and Collins) using a PCR probe test. Antonie Van Leeuwenhoek 1993, 64(3-4):253-260.

12. Beneduzi A, Campos S, Ambrosini A, de Souza R, Granada C, Costa P, Arruda L, Moreira F, Vargas LK, Weiss V, Tieppo E, Faoro H, Souza EM, Pedrosa FO, Passaglia LM: Genome sequence of the diazotrophic Gram-positive rhizobacterium Paenibacillus riograndensis SBR5(T). J Bacteriol 2011, 193(22):6391-6392.

13. Ma Y, Xia Z, Liu X, Chen S: Paenibacillus sabinae sp. nov., a nitrogen-fixing species isolated from the rhizosphere soils of shrubs. Int J Syst Evol Microbiol 2007, 57(Pt 1):6-11.

14. Seldin L, Van Elsas JD, Penido EGC: Bacillus azotofixans sp. nov., a nitrogen-fixing species from Brazilian soils and grass roots. Int I Syst Bacteriol 1984, 34:451-456.

15. Ma M, Wang C, Ding $Y$, Li L, Shen D, Jiang X, Guan D, Cao F, Chen H, Feng R, Wang X, Ge Y, Yao L, Bing X, Yang X, Li J, Du B: Complete genome sequence of Paenibacillus polymyxa SC2, a strain of plant growth-promoting rhizobacterium with broad-spectrum antimicrobial activity. J Bacterio/ 2011 193(1):311-312.

16. Yan Y, Yang J, Dou Y, Chen M, Ping S, Peng J, Lu W, Zhang W, Yao Z, Li H, Liu W, He S, Geng L, Zhang X, Yang F, Yu H, Zhan Y, Li D, Lin Z, Wang Y, Elmerrich C, Lin $M$, Jin Q: Nitrogen fixation island and rhizosphere competence traits in the genome of root-associated Pseudomonas stutzeri A1501. Proc Natl Acad Sci U S A 2008, 105(21):7564-7569.

17. Oh CJ, Kim HB, Kim J, Kim WJ, Lee H, An CS: Organization of nif gene cluster in Frankia sp. EulK1 strain, a symbiont of Elaeagnus umbellata. Arch Microbiol 2012, 194(1):29-34

18. Welsh EA, Liberton M, Stockel J, Loh T, Elvitigala T, Wang C, Wollam A, Fulton RS, Clifton SW, Jacobs JM, Aurora R, Ghosh BK, Sherman LA, Smith RD, Wilson RK, Pakrasi HB: The genome of Cyanothece 51142, a unicellular diazotrophic cyanobacterium important in the marine nitrogen cycle. Proc Natl Acad Sci U S A 2008, 105(39):15094-15099.

19. Xie JB, Du Z, Bai L, Tian C, Zhang Y, Xie J, Wang T, Liu X, Chen X, Cheng Q Chen S, Li J: Comparative genomic analysis of $\mathrm{N}_{2}$-fixing and non- $\mathrm{N}_{2}$-fixing Paenibacillus spp.: organization, evolution and expression of the nitrogen fixation genes. PLoS Genet 2014, 10(3):e1004231. 
20. Wang L, Zhang L, Liu Z, Zhao D, Liu X, Zhng B, Xie J, Hong Y, Li P, Chen S, Dixon $R$, Li J: A minimal nitrogen fixation gene cluster from Paenibacillus sp. WLY78 enables expression of active nitrogenase in Escherichia coli. PLoS Genet 2013, 9:e1003865.

21. Bothe H, Schmitz O, Yates MG, Newton WE: Nitrogen fixation and hydrogen metabolism in cyanobacteria. Microbiol Mol Biol Rev 2010, 74(4):529-551.

22. Leigh JA: Nitrogen fixation in methanogens: the archaeal perspective. Curr Issues Mol Biol 2000, 2(4):125-131.

23. Touchon M, Rocha EP: Causes of insertion sequences abundance in prokaryotic genomes. Mol Biol Evol 2007, 24(4):969-981.

24. Francino MP: An adaptive radiation model for the origin of new gene functions. Nat Genet 2005, 37(6):573-577.

25. Pedrosa FO, Monteiro RA, Wassem R, Cruz LM, Ayub RA, Colauto NB, Fernandez MA, Fungaro MH, Grisard EC, Hungria M, Madeira HM, Nodari RO, Osaku CA, Petzl-Erller ML, Terenzi H, Vieira LG, Steffens MB, Weiss VA, Pereira LF, Almeida MI, Alves LR, Marin A, Araujo LM, Balsanelli E, Baura VA, Chubatsu LS, Faoro H, Favetti A, Friedermann G, Glienke C, et al: Genome of Herbaspirillum seropedicae strain SmR1, a specialized diazotrophic endophyte of tropical grasses. PLoS Genet 2011, 7(5):e1002064.

26. Guo Q, Peng T, Chang T, Zhang G, Jiang W, Li Y, Li J: Mutagenesis at a-423lle of MoFe protein reduces the catalytic activity of nitrogenase in Klebsiella oxytoca. Chin Sci Bull 2014, 59:849-856.

27. Hong Y, Ma Y, Wu L, Maki M, Qin W, Chen S: Characterization and analysis of nifH genes from Paenibacillus sabinae T27. Microbiol Res 2012, 167(10):596-601.

28. Enkh-Amgalan J, Kawasaki H, Oh-oka H, Seki T: Cloning and characterization of a novel gene involved in nitrogen fixation in Heliobacterium chlorum: a possible regulatory gene. Arch Microbiol 2006, 186(4):327-337.

29. Kessler PS, Blank C, Leigh JA: The nif gene operon of the methanogenic archaeon Methanococcus maripaludis. J Bacterio/ 1998, 180(6):1504-1511.

30. Dodsworth JA, Leigh JA: Regulation of nitrogenase by 2-oxoglutarate-reversible, direct binding of a PII-like nitrogen sensor protein to dinitrogenase. Proc Natl Acad Sci U S A 2006, 103(26):9779-9784.

31. Dixon R, Kahn D: Genetic regulation of biological nitrogen fixation. Nature Rev Microbiol 2004, 2(8):621-631.

32. Yamada M, Kubo M, Miyake T, Sakaguchi R, Higo Y, Imanaka T: Promoter sequence analysis in Bacillus and Escherichia: construction of strong promoters in E. coli. Gene 1991, 99(1):109-114.

33. Jarmer H, Larsen TS, Krogh A, Saxild HH, Brunak S, Knudsen S: Sigma A recognition sites in the Bacillus subtilis genome. Microbiology 2001, 147(Pt 9):2417-2424

34. Dilworth MJ: Acetylene reduction by nitrogen-fixing preparations from Clostridium pasteurianum. Biochim Biophys Acta 1966, 127(2):285-294.

35. Schollhorn R, Burris RH: Acetylene as a competitive inhibitor of $\mathrm{N}_{2}$ fixation. Proc Natl Acad Sci U S A 1967, 58(1):213-216.

36. Montoya JP, Voss M, Kahler P, Capone DG: A simple, high-precision, high-sensitivity tracer assay for N(inf2) fixation. Appl Environ Microbiol 1996, 62(3):986-993.

37. Guindon S, Dufayard J, Lefort V, Anisimova M, Hordijk W, Gascuel O: New algorithms and methods to estimate maximum-likelihood phylogenies: assessing the performance of PhyML 3.0. Syst Biol 2010, 59:307-321.

38. Thompson JD, Gibson T, Higgins DG: Multiple sequence alignment using ClustalW and ClustalX. Curr Protoc Bioinformatics 2002, 00:2.3:2.3.1-2.3.22.

39. Lagesen K, Hallin P, Rodland EA, Staerfeldt HH, Rognes T, Ussery DW: RNAmmer: consistent and rapid annotation of ribosomal RNA genes. Nucleic Acids Res 2007, 35(9):3100-3108.

40. Lowe TM, Eddy SR: tRNAscan-SE: a program for improved detection of transfer RNA genes in genomic sequence. Nucleic Acids Res 1997, 25(5):955-964

41. Finn RD, Mistry J, Tate J, Coggill P, Heger A, Pollington JE, Gavin OL, Gunasekaran P, Ceric G, Forslund K, Holm L, Sonnhammer EL, Eddy SR, Bateman A: The Pfam protein families database. Nucleic Acids Res 2010 38(Database issue):D211-D222.

\section{doi:10.1186/1471-2164-15-723}

Cite this article as: Li et al:: The genome of Paenibacillus sabinae T27 provides insight into evolution, organization and functional elucidation of nif and nif-like genes. BMC Genomics 2014 15:723.

\section{Submit your next manuscript to BioMed Central and take full advantage of:}

- Convenient online submission

- Thorough peer review

- No space constraints or color figure charges

- Immediate publication on acceptance

- Inclusion in PubMed, CAS, Scopus and Google Scholar

- Research which is freely available for redistribution

Submit your manuscript at www.biomedcentral.com/submit
C) Biomed Central 